\title{
Assessment of biological safety: A social and legal aspect
}

\author{
O.V. Volosyanko', V.I. Kurylo , M.Yu. Kravchuk ${ }^{2 *}$ \\ ${ }^{1}$ National University of Life and Environmental Sciences of Ukraine \\ Heroiv Oborony St.15, Kyiv, Ukraine, 03041 \\ ${ }^{2}$ Ternopil National Economic University \\ Lvivska St. 11, Ternopil, Ukraine, 46000 \\ *Corresponding author E-mail: vitmarianna@ukr.net
}

Received: 15.10.2019. Accepted: 29.10.2019

\begin{abstract}
The article is dealed with problems and prospects of experiments with biological objects directed on change of a natural hereditary basis, which include risks of creation of new unnatural living organisms that can represent biological danger to the humans and environment. We noted that the possibility of uncontrolled creation of high/y pathogenic strains of microorganisms, which do not exist in nature, for humans or animals, poses a great threat. We considered that such nelv pathogenic strains should be dangerous to the environment and will inevitably endanger human and animal life on the planet. There are several quite convincing examples in the world illustrated the danger of invading the genetic program of a living organism, while ignoring the laws of evolution and genetics, focusing only on short-term financial benefits to individuals, companies or financial groups. We established that a key element in preventing the spread of infection from laboratories or other artificial places of consolidation is the strict implementation of standard microbiological requirements. The development of effective measures to prevent and eliminate the consequences of biological attacks, taking into account their various possible scenarios, should be based on biomedical, social, economic and legal criteria. We suggested we need to consider the cost-benefit analysis and other indices characterizing the state of ecology, economy, health, and social relations when implement the measures on biological safety. In Ukraine today there is a priority to develop a legislative position in the field of counteraction to bioterrorism. This issue concerns not only the development and adoption of special laws, but also the implementation of the policy of "efficiency" against biological threats by the relevant state authorities. This also includes the establishment of full state control over enterprises and institutions related to biological agents and toxins, and the improvement of the system of "state-scientist" to control the leakage of professional knowledge outside the country.
\end{abstract}

Key words: Biotechnology; Genetically modified organisms; Biological risks; Biosafety

\section{Introduction}

Experiments with biological objects, aiming for changing the natural hereditary basis, could include the risks of creating new unnatural living organisms, which may pose a biological hazard to humans and the environment. Nowadays, very important task is the creation of international and national contro/ over the potentially dangerous scientific experiments in the biological field. In reality, large number of research institutions and university departments abroad and in Ukraine plan and carry out experiments with high biological risk and capable of leading to disasters of biological origin (emergence of new deadly diseases for humans and new deadly enemies for useful living organisms) - see Velichko and Radchenko (2016).

The main purpose of experiments on the transformation of plastid DNA is to achieve a state of stable transformation. With stable chloroplast transformation, all copies of the plastid genome are transformed, i.e. in a homoplastid condition, while copies of the wild type of plastid genome (with non-transformed DNA) are excluded from the selection process. We believe that it is necessary to attract public attention and activate law-making activities in order to ensure unconditional state control and introduction of responsibility at the legislative level for potentially dangerous biological experiments.

\section{Literature Review}

There are plenty of examples in history of experiments without assessing the potential biological and economic risks, where the introduction of animals and plants has led to environmental disasters. The introduction of rabbits to Australia; the introduction of wild rabbits from Australia to England, which has caused which caused an outbreak of mixomatosis of rabbits in most European countries; anthropogenic influx of milkweed to America, where it became the main weed with no natural pests; the importation of wild wasps from Germany to Australia, where this species creates huge colonies, reaching up to 1 million individuals, not only significantly affecting ecosystems but also capable of attacking humans. A similar case is the appearance of an African killer bee in America, which eventually resulted in the rash introduction of an African subspecies of honeybees (Apis mellifera adansoni) into Brazil, implemented by the geneticist V.E. Kerrom (Radchenko and Pasenko, 1994). As a result of negligence, several African bee families, which had crossed with the European race cultivated in America, were released uncontrolled from the laboratory into the environment. The result is an incredibly aggressive hybrid that can kill people and livestock. The hybrid has now spread widely across America, and its range is expanding rapidly.

One more example of dangerous research was done with microorganisms. Thus, during the conference in Malta, the Dutch geneticist Ron Fouchier from the Erasmus University in Rotterdam reported on a sensational discovery made by his research team. Only a few minor changes made by scientists in the genome of the avian influenza H5N1 virus have allowed it capable to infect 
humans by airborne droplets, i.e. it has been made easily transmissible from person to person (Herfst et al, 2012). Avian influenza is a highly dangerous infectious disease. For example, recent outbreaks during 2009-2012 have taken 500 lives worldwide. However, the vast majority of those affected were found to have direct contact with the blood of sick birds. In particular, the airborne transmission of the virus from person to person in its present, natural form does not occur at all. Therefore, the formation of a transgenic strain of avian influenza virus with the ability to be transmitted from an infected person to a healthy person makes it highly pathogenic for humans.

It is estimated that the $\mathrm{A} / \mathrm{H} 5 \mathrm{~N} 1$ virus, when transmitted from person to person, can lead to a pandemic that could take the lives of 40 million people. Compared to it, AIDS seems to be a common cold, while the new Spaniard, transformed with the gene of ordinary avian flu, could be the new "Black Death" in the XXI century!

At the same time, a similar independent study was carried out in the United States (University of Wisconsin-Madison). American scientists have found a specific set of agents in the influenza virus genome, where there are those genes that provide the specified pathogen property to be transmitted by airborne mechanism. In fact, scientists have shown how to create pathogens, including avian influenza, more infectious, thanks to the simplified mechanism of their transmission. Having established a group of genes responsible for the property of viral disease to be transmitted through this mechanism, researchers have also invented a new effective way to combat infections (due to the blocking of these genes of natural viral infections transmitted to humans in this way). Biologists have paved the way for the possibility of saving humanity from annual influenza epidemics, which, although less pathogenic than $\mathrm{A} / \mathrm{H} 5 \mathrm{~N} 1$, cause more harm to human health and often lead to death. The rapid development of global biotechnology has simultaneously created new and higher levels of biological risks. In 2002, in Department of Zoology of the Donetsk National University (Ukraine) the experiments to infect flour beetles with some of the simplest single-celled parasitic microorganisms - Sporozoa, which are pathogens of deadly diseases, were carried out. Most parasites are not yet known because of the lack of hosts that can actually transmit them to humans. The hosts of these parasites are gophers and some species of insects that are potentially unable to enter the human food chain. Experimenters have tried to check whether the pathogens can survive in larvae and adults of the flour beetle, which can then be relatively easily ingested (through untreated flour products) and infested. In the course of the experiment, scientists were able to infect flour beetles and make them to be the hosts of a number of pathogens. Nevertheless, the experiment was stopped and the infected insects (adult insects and larvae of the beetle) were eliminated.

Ukrainian scientists from the Institute of Zoology of the National Academv of Sciences conducted experiments on infecting larvae and pupae of honey bees with a dangerous pest - chalcides (Melittobia acasta), which was never found in the families of honey bees in nature. The experiment also went well (Doroshina, 1988). This wasp effectively destroyed the offspring of bees. It is well known that young wasps remember the smell of their hosts from birth and are therefore able to move on to new foods - in this case, honey bees, which may not be able to fight this wasp. Such a transition to parasitizing on honey bees can cause more damage to beekeeping than varroatosis. Varroatosis, in turn, is of anthropogenic origin - a parasite (Varroa destructor) has been exposed to honey bees as a result of re-introduction experiments in Europe of primary European bee races. They were brought there from the Russian Far East, where they were "infected" by a Chinese wax bee, which was the primary carrier of this parasite at the time (Pasenko et al., 1989).

In 2003, at the Department of Zoology of Shevchenko National Research University they successfully conducted experiments to infect cyclops (which have important habitat significance) with the simplest parasitic microsporidia, which lead to the death of their hosts. Moreover, they used the Microsporidium species that are not parasites of cyclops in nature. The possibility of uncontrolled creation of highly pathogenic strains of microorganisms that do not exist in nature, either human or animal, poses a major threat. These new pathogenic strains are dangerous to the environment and inevitably pose a real threat to human and animal life on the planet.

This is evidenced by the fact that information on the decoding of the genetic code for the genomes of Ebola or smallpox viruses and other pathogens is in open access and can be used for terrorist purposes. Genes, present in nature have long been synthesized by humans and are freely available in specialized online catalogues. Therefore, biohackers, using available scientific information should construct a new genome that would pose a biologicai threat.

Currently, there are quite convincing examples in the world of how dangerous it is to interfere in the genetic program of a living organism, ignoring the laws of evolution and genetics, focusing only on short-term financial benefits for individuals, companies or financial groups. This use and spread of possible biological risks in the application of GMOs requires not only the cessation of genetic engineering, but also large-scale monitoring studies of the spread of transgenic plants, the transition to the creation of safe GMO plants. Food and Agricultural Organization of United Nations directly follows the rules of implementation of the precautionary principle, which is formulated in the United Nations Declaration on Environment and Sustainable Development (signed in Rio de Janeiro in 1992, see Kaczyński and Egorov, 2009).

It is important to avoid potential risks to people and the environment when using GMOs by providing evidence of the safety of transgenic plants and their derivatives from the producer before commercial use. Objective reasons for the existence of real and potential biological risks from the creation and use of GMOs, such as the transport of transgenes, are unpredictable and may be accompanied by disruption of the work of this or other genes ("gene transfer effect"), as well as changes in cellular metabolism with the possible formation of substances with negative biological effects. An accidentally embedded alien gene may affect the performance of other genes, the consequences of which cannot be predicted. One of the main drawbacks of modern gene technologies is the presence of a built-in DNA fragment, except for the so-called "target gene", which changes this or that property of the organism, "technological garbage", including genetic resistance to antibiotics (Kuchuk, 1997).

\section{Discussion}

In Ukraine, the level of use of biotechnological products is low in comparison with developed countries. According to experts, the volume of production of the Ukrainian biotechnology sector today does not exceed 20 million US dollars. Thus, in the pharmaceutical industry, the share of domestic production in the market of immune biotechnological drugs is only $9 \%$, and the industrial biotechnology sector is even less developed (Bloom et al., 2006). In recent years, the Institute of Cell Biology and Genetic Engineering of the National Academy of Sciences of Ukraine, within the framework of studies to control the spread of transgenic plants, has monitored one hundred of the most used maize breeding lines in the Dnipropetrovsk region for the presence of spontaneously recorded 16 transformational cases registered in the European Union. As a result, among the analyzed breeding lines twenty transformation events with ID Bt176 were found. The analysis of 100 samples of maize from the Kiev retail network revealed 
two cases of event MON 810. In 100 samples from Cherkasy region three cases of GA21 (2011) transformation events were revealed (Morgun et al., 2011).

A certain danger of using transgenic organisms, including plants, is related to the fact that the transferred genes can move uncontrolled into the environment along with pollen. Such movement of genes can contribute to the transformation of weed genomes and thus lead to the creation of harmful plants resistant to herbicides. The way out of this situation is to create herbicide resistant agricultural plants by converting chloroplast DNA rather than nuclear DNA. In this case, pollen will not contain foreign genes transferred to plants, and uncontrolled spread of transgenes in the environment will be excluded. Chloroplast transformation is a method of targeted integration of an alien gene or genes into the plastic genome by homologous recombination. Compared to nuclear, chloroplast transformation has a number of undeniable advantages: a high level of expression and the possibility of accumulation of a significantly larger amount of protein product compared to the expression of the same gene contained in the nuclear DNA. Alien proteins in cells with transformable chloroplast DNA can be synthesized in large quantities, accounting for up to $40 \%$ of the total soluble cellular protein (Cosa et al., 2001). This was found in studies of the transformation process during the transfer of B-glucuronidase and neomycin phosphotransferase II genes (Staub et Maliga, 1992). The precise incorporation of the gene, moving, makes it possible to avoid the influence of uncontrolled position effects or "silence" of the transferred genes, which is typical for the transformation of nuclear DNA (Kooter et al, 1999).

The main purpose of experiments on the transformation of plastome DNA is to achieve a state of stable transformation. With stable chloroplast changes, all copies of the plastic genome are transformed, i.e., in a homoplastid state, while copies of wild type plastic genome (with non-transformed DNA) are excluded in the selection process. Stable transformation of tobacco chloroplast DNA was carried out in 1990 (Svab et al., 1990) by bombardment of tungsten leaf explosives by plasmid DNA particles and PEG (polyethylene glycol). Reliable, reproducible protocols for chloroplast DNA conversion have been developed only for plants of the genus Nicotiana. Chloroplast transformation of other valuable crops, such as potatoes, tomatoes, cabbage, corn and others, is still difficult. There are reports of successful changes in chloroplast DNA from a limited number of species, such as Lycopersicon esculentum, Lesguerella fendleri, Petunia hybrida, Glycine max and others (2009) (Matveeva, 2009). Most of the activity on transformation of plant chloroplast DNA was done using the bombing method. In this way, transplastomic potatoes plants (Sidorov et al., 1999), tomatoes plants (Ruf et al., 2001), transplastomic Arabidopsis (Sikdar et al., 1998), and petunias (Zubko et al., 2004) were obtained. Successful transformation of the Brassica napus and Brassica oleracea var. botrytis plastic genomes has been reported (Hou BingKai et al, 2003). Transplastomic lettuce plants were also obtained by bombardment (Kamamoto et al, 2006), where all transplastomic T0 plants were fertile and the T1 progeny uniformly showed stability of the transgene in the chloroplast genome.

The PEG-induced transformation also belongs to the methods of producing transformed plastids. As well as biolistic transformation, it is based on the principle of direct transfer of the isolated DNA (Koop et al., 1993). The main condition in preventing the spread of infection from laboratories or other artificial places of its consolidation is the strict implementation of standard microbiological requirements. Researchers working with infectious materials should be aware of the level of danger to personal life and health, personal responsibility for the leakage of infection into the environment. To prevent this, scientists must have a high level of training and practical skills for safe handling of materials (Vydayko, 2004). Biological laboratories of high risk include biotechnology, clinical laboratories, diagnostic facilities, regional or national reference centers, health system laboratories, research centers (training, pharmaceutical, environmental), and manufacturing facilities (vaccine manufacturers, pharmaceutical manufacturers, large-scale GMO producers) working in the fields of genetic engineering, medicine, veterinary medicine and agriculture (Vinograd, 2004). The development of effective measures to prevent and eliminate the consequences of biological terrorist acts, taking into account their various possible scenarios, should be based on biomedical, social, economic, and legal criteria. A cost-benefit analysis and other indices characterizing the state of the environment, economy, health and social relations should be also considered. Ukraine today announces the priority of formation of regulatory legai acts in the field of counteraction to bioterrorism. This issue concerns not only the development and adoption of special laws, but also the implementation of the policy of "effectiveness" against biological threats by the relevant state authorities; the establishment of full state control over enterprises and institutions related to biological agents and toxins; improvement of the system "state-scientist" to limit the leakage of professional knowledge outside the country and understanding of threat assessment.

\section{Conclusion}

Uncontrolled release of transgenic organisms into the environment may cause disruption of the biological balance and cause some harm to biodiversity. In the case of transgenic plants, the potential risks of artificial genetic transfer to the genotype of existing organisms and the emergence of more viable pests may displace other organisms from their ecological niches and contribute to the spread of antibiotic-resistant pathogens, new proteins and biologically active substances harmful to humans and animals. Evidence of biosafety of genetically modified organisms and products derived from them should outpace their commercial use. We believe that the consolidation of efforts of the entire international community should prevent the bioterrorism. We consider it expedient to adopt of the Law of Ukraine, which would clearly define the specific state bodies, their goals, objectives, and functions in relation to preventing biological threats.

\section{References}

Hou, B.K., Zhou, Y.H., Wan, L.H., Zhang, Z.L., Shen, G.F., Chenm Z.H., Hu, Z.M. (2003). Chloroplast transformation in oilseed rape. Transgen. Really. 2003. 12(1), 111-114.

Biological safety of Ukraine. (2016). M.V. Velichko, V.G. Radchenko (Eds.). Kyiv: National Academy of Science (in Ukrainian)

Blum, Y., Sivolap, Y., Sozinov, O. (2006). The New Wave of the Green Revolution (Prospects for the Application of Molecular Biology and Genomics in Ukraine). Bulletin of the National Academy of Sciences of Ukraine, 3, 21-31. (in Ukrainian)

Cosa, B., Moar, W., Lee, S.B., Miller, M., Daniell, H. (2001). Overexpression of Bt cry2Aa2 operon in chloroplast leads to the formation ofinsecticidal crystals. Nat. Biotechnol., 19(1), 71-74.

Doroshina, L.V. (1988). Melitobia is a potential pest of honeybees. Apiculture. Moscow (in Russian)., 1988.

Herfst, S., Schrauwen, E.J., Linster, M., Chutinimitkul, S., de Wit, E.....Fouchier, R.A. (2012). Airborne transmission of Influenza A/H5N1 virus between ferrets. Science, 336(6088), 1534-1541.

Kachinsky, A.B., Egorov, Yu.V. (2009). Ecological safety of Ukraine: system principles and methods of its formalization. National security: the Ukrainian dimension, 4(23), 71-79. (in Ukrainian) 
Kanamoto, H., Yamashita, A., Asao, H., Okumura, S., Takase, H., ... Tomizawa, K. (2005). Efficient and Stable Transformation of Lactuca sativa L. Cv. Cisco (lettuce) Plastids. Transgenic Research, 15, 205-217.

Kooter, J.M., Matzke, M.A., Meyer, P. (1999). Listening to the silent genes: transgene silencing, gene regulation and pathogen control. Trends Plant Sci., 4(9), 340-347.

Kuchuk, N.V. (1997). Genetic engineering of higher plants. Kiev. Naukova Dumka (in Russian).

Kumar, S., A. Dhingra, H. Daniell, H. (2004). Stable transformation of the cotton plastid genome and maternal inheritance of transgenes. Plant Mol. Biol, 56(2), 203-216.

Matveeva, H.A. (2009). Transformation of the chloroplast DNA of plants of the Solenaceae family: achievements and prospects. Visnyk of Ukrainian Geneticists and Breeders, 7(2), 289-304. (in Ukrianian)

Morgun, B.V., Bannikova, M.O., Satarova, T.M., Borisova, V.V., Kuchuk, M.V. (2011). Method of determining transgenic line GA21 of corn by polymerase chain reaction. Utility Model Patent No. 61602. Registered in the State Register of Utility Patents of Ukraine on 25.07.2011. (in Ukrainian)

O'Neill, C., Horváth, G.V., Horváth, E., Dix, P.J., Medgyesy, P. (1993). Chloroplast transformation in plants: polyethylene glycol (PEG) treatment of protoplasts is an alternative to biolistic delivery systems. Plant J., 3(5), 729-738.

Pesenko, Yu.A., Leley, A.S., Radchenko, V.G., Filatkin, G.N. (1989). Chinese beeswax Apis cerana cerana F. (Hymenoptera, Apoidea) in the Far East of the USSR. Entomological review, 68(3), 527-548. (in Russian)

Que, Q., Elumalai, S., Li, X., Zhong, H., Nalapalli, S., Schweiner, M., ... Chilton, M. D. (2014). Maize transformation technology development for commercial event generation. Frontiers in plant science, 5, 379. doi:10.3389/fpls.2014.00379

Radchenko, V.G., Pesenko, Yu.A., (1994). Bee biology (Hymenoptera, Apoidea). St. Petersburg: Zoology Institute of Russian Academy of Science (in Russian)

Ruf, S., Hermann, M., Berger, I.J., Carrer, H., Bock, R. (2001). Stable genetic transformation of tomato plastids and expression of a foreign protein in fruit. Nat. Biotechnol, 19(9), 870-875.

Sidorov, V.A., Kasten, D., Pang, S.Z., Hajdukiewicz, P.T., Staub, J.M., Nehra, N.S. (1999). Stable chloroplast transformation in potato: use of green fluorescent protein as a plastid marker. Plant J. 1999, 19(2), 209-216.

Sikdar, S.R., Serino, G., Chaudhuri, S., Maliga, P. (1998). Plastid transformation in Arabidopsis thaliana. Plant Cell Rep., 18(1-2), 20-24.

Staub, J.M., Maliga, P. (1992). Accumulation of D1 polypeptide in tobacco plastids is regulated via the untranslated region of the psbA mRNA. EMBO J, 12(2), 601-606.

Svab, Z., Hajdukiewitz, P., Maliga, P. (1990). Stable transformation of plastids in higher plants. Proc. Nat. Acad. Sci. USA. 1990. Vol. 87, N 21. P. 8526-8530.

Vinograd, N.A. (2004). Aspects of biological safety of Ukraine: problems laboratories included in the surveillance system for particularly (September-October 2004, Donetsk). Donetsk, 2004. pp. 44-45. (in Russian)

Yu, Q., Lutz, K. A., \& Maliga, P. (2017). Efficient Plastid Transformation in Arabidopsis. Plant physiology, 175(1), 186-193. doi:10.1104/pp.17.00857

Zubko K.M., Zubko, E.I., Van Zuilen, K., Meyer, P., Day, A. (2004). Stable transformation of petunia plastids. Transgen. Really, 13(6), 523530.

\section{Citation:}

Volosyanko, O.V., Kurilo, V.I., Kravchuk, M.Y. (2019). Assessment of biological safety: A social and legal aspect. Ukrainian Journal of Ecology, 9(3), 227-230.

(cc) $\mathbf{E Y}$

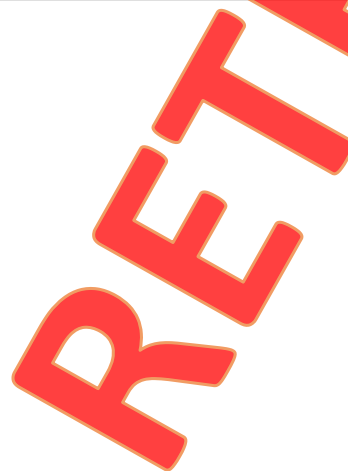

